\title{
THE PROBLEM OF TEMPORAL VALIDITY OF REFERENCE COORDINATES IN THE CONTEXT OF RELIABILITY OF THE ETRS89 SYSTEM REALIZATION IN POLAND
}

\author{
K. Szafranek \\ Military University of Technology
}

\begin{abstract}
The IAG (International Association of Geodesy) Sub-Commission for the European reference frame (EUREF) passed a resolution recommending application of the ETRF2000 frame as national realizations of the ETRS89 reference system during the $\mathrm{XX}^{\text {th }}$ EUREF Symposium in Gävle (Sweden) in 2010. The PL-ETRF2000 system is comprised of EPN (EUREF Permanent Network) sites. Their coordinates and their temporal changes (velocities) were accurately determined on the basis of long-term GNSS observations. The transfer of the PLETRF2000 system onto the territory of Poland is realized by the ASG-EUPOS (Active Geodetic Network - European Position Determination System) permanent sites network. The ASG-EUPOS tasks include also system maintenance by continuous or periodical control of the coordinates and velocities constancy.
\end{abstract}

According to the current Regulation of the Ministry of Administration and Digitization concerning geodesic, gravimetric and magnetic warps, the accuracy of sites of the fundamental warp (EPN sites belonging to ASG-EUPOS) may not be worse than $0.01 \mathrm{~m}$ for horizontal position and $0.02 \mathrm{~m}$ for geodesic height. It results in the necessity to monitor the performance of the reference sites for proper maintenance of the reference system.

A new team for modeling deformations in Europe was established within the EUREF Working Group (The EUREF Working Group on Deformation Models) during the EUREF 2012 Symposium in Paris. One of its tasks is taking geo-kinematic models into consideration for national realizations of the ETRS89 and maximum usage of knowledge concerning the velocity field.

The paper deals with the problem of temporal validity of the catalogue coordinates and the necessity of periodical updating them on the basis of velocities derived from long-term observations. Although Poland is located in a tectonically calm area and the intraplate velocities are small, some of the EPN and ASG-EUPOS sites have significant velocities and are subject to vertical movements. Lack of periodical updating of the coordinates realizing the reference system will cause lack of fulfillment of the assumed accuracy criterion.

Analysis of horizontal and vertical velocities of sites belonging to the fundamental warp lead to assumption that two sites will exceed horizontal criterion in a period of time shorter than 10 years counting from the reference epoch (i.e. from 2011.0): KATO horizontal coordinates should be updated in 2014 and GWWL in 2021. Mores sites will exceed vertical 
criterion: BOGI (2021), GWWL (2015), KATO (2019), SWKI (2019) and ZYWI (2021). The vertical component updating will require of course changes of the horizontal component (coordinates are determined in the Cartesian orthogonal XYZ coordinate system and then recalculated for the ellipsoidal coordinates). Besides periodical coordinates updating it is recommended to conduct repeated processing for the entire network according to the EUREF standards for taking the current GNSS observations into consideration.

Keywords: ASG-EUPOS, ETRS89, ETRF, reference frame, coordinates'stability

\section{INTRODUCTION}

Permanent GNSS networks (Global Navigation Satellite System) like the IGS (International GNSS System, http://igscb.jpl.nasa.gov/), the EPN (EUREF Permanent Network, http://www.epncb.oma.be) or the Polish ASG-EUPOS system (Active Geodetic Network European Position Determination System, http://www.asgeupos.pl/) radically changed the way the global reference systems are defined and realized. Long-term observations conducted at the permanent GNSS sites constitute the basis for reliable determination of their coordinates and their temporal changes, i.e. velocities, as well. They are expressed in the global ITRF system (International Terrestrial Reference Frame) which is a practical realization of the ITRS system (International Terrestrial Reference System) created using observations done by means of four techniques (besides the GNSS, the SLR - Satellite Laser Ranging, the DORIS - Doppler Orbitography and Radiopositioning Integrated by Satellite and the space VLBI technique - Very Long Baseline Interferometry are used here). Furthermore, permanent GNSS observations enabled to create the global velocity field which enables to verify the theoretical models applied so far. The global velocity field is made denser using regional solutions (Working Group on Regional Dense Velocity Fields, http://epncb.oma.be/IAG/) and local networks like EPN and ASG-EUPOS which causes that the current reference systems have become kinematic, and reliable determination of the velocities of the individual sites is crucial for their maintenance.

In response to the requirement for systematizing the reference systems used in Poland, the Polish government issued a Regulation concerning the national system of spatial references. This Regulation implements the PL-ETRF2000 and PL-ETRF89 as frames constituting the national spatial reference system. Another Regulation of the Ministry of Administration and Digitalization concerning geodesic, gravimetric and magnetic warps introduces a new classification of geodesic warps in Poland taking into consideration the increasing importance and specificity of the GNSS measurements. It also defines the accuracy requirements for the sites constituting the geodesic warp (main and detailed).

A new team for modeling deformations in Europe was established within the EUREF Working Group (The EUREF Working Group on Deformation Models, (Lidberg, 2012)) during the EUREF 2012 Symposium in Paris. One of its tasks is taking geo-kinematic models into consideration for national realizations of the ETRS89. The paper is aimed to analyze the temporal validity of the coordinates of Polish permanent sites (EPN and ASG-EUPOS) taking into consideration the sites velocities obtained on the basis of long-term observations and the accuracy requirements defined in legal regulations. The paper also specifies when the change of the catalogue values of coordinates (constituting among others reference for differential measurements) is necessary. 


\section{LEGAL ASPECTS OF REFERENCE SYSTEMS AND WARPS IN POLAND}

IAG (International Association of Geodesy) Sub-Commission for the European reference frame (EUREF) passed a resolution recommending application of the ETRF2000 frame as national realizations of the ETRS89 reference system during the $X^{\text {th }}$ EUREF Symposium in Gävle, Sweden in 2010. EUREF Working Group also published recommendations concerning the EUREF densifications (Bruyninx et al., 2009). It describes computational strategy of determining the sites coordinates expressed in the realization of the ETRS89, mainly for national realizations of the system, i.e. making the EPN network denser. The strategy was used in computations concerning processing of GNSS observations from the ASG-EUPOS system (Figurski et al., 2009, 2010) conducted in the Centre of Applied Geomatics of the Military University of Technology.

According to the Resolution, the new Regulation of the Polish Government concerning national spatial reference system will implement the PL-ETRF2000 and PL-ETRF89 geodesic reference frames constituting the national spatial reference system. The PL-ETRF2000 is composed of the network of permanent EPN sites (and of those belonging to the ASGEUPOS) with accurately determined coordinates and their temporal changes (15 sites in Poland). The transfer of the PL-ETRF2000 system onto the territory of Poland is realized by the ASG-EUPOS permanent sites network. The ASG-EUPOS tasks include also system maintenance by continuous or periodical control of the coordinates and velocities constancy. The PL-ETRF89 is transferred onto the territory of Poland and maintained on the basis of GNSS observations using the network of sites of the main geodesic warp which is defined by the Regulation of the Ministry of Administration and Digitalization concerning geodesic, gravimetric and magnetic warps. The regulation introduces a new classification of horizontal geodesic warps dividing them into the main and detailed ones.

The coordinates of the main horizontal warp are determined using GNSS satellite measurements. It is divided into the fundamental warp transferring the ETRF2000 system onto the territory of Poland and the base warp making the system denser. The fundamental warp is composed of the ASG-EUPOS reference sites which belong to the EPN permanent sites network and which average position determination errors may not exceed $0.01 \mathrm{~m}$ for horizontal position and $0.02 \mathrm{~m}$ for vertical component. The base warp comprises the remaining sites of the ASG-EUPOS system, the EUREF-POL sites (11 sites which coordinates were determined in 1992 using satellite measurements), the POLREF sites (348 sites related to the EUREF-POL sites in 1994-1995), EUVN network sites (62 sites of the European Vertical Reference Network which coordinates were determined in the ETRF system, and the heights in the EVRS07 - European Vertical Reference System), the sites of the astronomic-geodesic network and the filling network.

The detailed horizontal warp enhances the main horizontal warp and is used to refer measurement warps and to conduct detailed geodesic measurements. The sites of the existing warp fulfilling the assumed accuracy criteria and new established sites, which average position error with respect to fiducial sites after adjusting is smaller than 0.07 , were numbered among this group. Most of the sites are established using the static observations of the satellite technique as fiducial sites on the basis of the ASG-EUPOS sites, so all errors at the permanent sites of the system (e.g. as the result of the sites' movement) will have impact on the accuracy of the new established sites of the warp. Determination of reliable coordinates of the ASGEUPOS system and maintaining the reference frame consisting in continuous or periodical control of the coordinates with taking into account sites' displacement is indispensable for assuring the warp consistency (main and detailed) in Poland. 
Application of the GNSS technique to determining coordinates for warps resulted in ceasing to use the term "warp order". The sites coordinates are determined using the same reference products (precise IGS orbits of the 'final' type and the Earth rotation parameters) and they are expressed in the same reference system (the ITRF2008 transformed onto the ETRF2000 according to the procedure described in (Altamimi and Boucher, 2008)). Application of the GNSS technique (provided the measurement and observation processing were done correctly) assures consistency and homogeneity of the warp.

\section{EUREF WG ON DEFORMATION MODELS}

Temporal validity of coordinates of the GNSS catalogue sites has recently become a more and more often discussed problem at the EUREF forum. The first analysis of this issue was presented in (Caporali et al., 2011) and it concerned forecasts of the ETRS89 coordinates changes on the basis of the knowledge of their linear temporal changes (site velocity). The authors took into consideration the intraplate velocities, i.e. velocities expressed with respect to the stable part of the Euro-Asian plate (in the European ETRF system). These velocities have significant values in some parts of Europe. In this connection, Elmar Brockmann of the TWG EUREF monitors discrepancies of the current coordinates obtained in the weekly regime on the basis of processing conducted in the Local Analysis Centers (LAC) with respect to their catalogue values in the ETRF2000. The authors of the study emphasize that the main aim of the entities dealing with the ETRS89 realization in the individual countries (in Poland it is the Head Office of Geodesy and Cartography (HOGC)) is adaption of such catalogue coordinates which would maintain their validity for the longest period of time, i.e. the current solutions from the reference sites should not differ from the catalogue coordinates more than the assumed criterion and consistency with the monitoring system should be maintained. In case of countries where the intraplate velocities have significant values (Greece, the region of Fennoscandia or the vicinity of the Mediterranean), it is recommended to introduce linear interpolation of the coordinates using the known velocities (in some countries this solution was applied for the vertical coordinate because of the uplift of Fennoscandia) or more frequent implementation of a new realization of the ETRS89 which, of course, requires periodically repeated determination of the catalogue coordinates. A forecast concerning exceeding the assumed accuracy criterion $(3 \mathrm{~cm}$ for the horizontal and vertical components) was prepared using the average horizontal and vertical velocities observed in the individual European countries. With respect to the horizontal component, it occurred that the catalogue coordinates in Greece and Slovenia would exceed the assumed criterion by 2012, and in Croatia and Portugal - by 2020. With respect to the vertical component, the soonest expiration of the coordinates validity will occur in the Scandinavian countries, Poland, Denmark and Croatia (in these countries the assumed criterion will be exceeded by 2020). These analyses, however, have been made for averaged values of the velocities in the individual countries and are of rough nature.

It is worth to emphasize that the criterion mentioned above $-3 \mathrm{~cm}$ for the horizontal components - is relatively mildly restrictive in comparison with the accuracies required for the fundamental warp in Poland. In some European countries (Germany, Switzerland, Austria, (Personal communications, 2012)) corrections of the coordinates are introduced as soon as discrepancies from the catalogue values are observed (a common criterion of $1 \mathrm{~cm}$ for the horizontal components and $2 \mathrm{~cm}$ for the vertical component is applied), however, this issue is still analyzed and there are no formal recommendations for it. In this connection, the main goals of the new established EUREF Working Group on Deformation Models were presented during the EUREF2012 Symposium in Paris in June 2012. Among others theses are (Lidberg, 2012): 
- to increase accuracy of the determined velocities and make the determined velocity field denser (the issue of determining the velocities in sites among the reference ones),

- to develop geo-kinematic models (it is the most important for the Mediterranean region, Fennoscandia and Greenland),

- to take the kinematic models into consideration for maintaining and using national realizations of the ETRS89.

\section{ASG-EUPOS REFERENCE SOLUTION AND NETWORK MONITORING}

Using four-year observations from ASG-EUPOS sites (the system officially started on June 2, 2008), the CAG of the MUT determined a cumulative solution and forwarded it to the HOGC as a proposal of the catalogue coordinates. The strategy of obtaining this solution was based on recommendations of the IGS and EUREF and in general was compatible with previous studies conducted by the CAG of the MUT. The GNSS observations were processed by means of the Bernese 5.0 program (Dach et al., 2007), and the weekly SINEX (Solution Independent Exchange Format) files were stacked into one cumulative solution (coordinates and velocities for each site) using the CATREF (Combination and Analysis of Terrestrial Reference Frames) program (Altamimi et al., 2004). Apart from the positions and their changes, the values of seven parameters of the Helmert transform (translation, rotation and scale) were obtained. These parameters have no physical interpretation but they prove the consistency of the solutions and their compatibility with the cumulative solution (which is a reference for each subsequent solution). The study took into consideration the causes of potential discontinuities in the time series of the coordinates (e.g. equipment replacements or introduction of a new reference system). In such cases the entire observation period for a site was divided into sub-periods. Independent values of coordinates (and velocities) were determined for each sub-period, which should be used as catalogue (reference) values in the sub-period. It means that every change at a site (e.g. replacement of an antenna) in consequence requires re-determining the reference coordinates and coordinates from the recent sub-period should then be used as current values. The procedure of processing and its results are compatible with the procedures applied in the EPN (Kenyeres, 2009), (Kenyeres, 2012). Detailed processing was described in (Szafranek et al., submitted in 2012). Fig. 1 presents a graphical comparison of the coordinates values obtained from processing of the ASG-EUPOS done by the CAG of the MUT and coordinates from the last official EPN solution (Kenyeres, 2012) which includes the cumulative solutions (coordinates and velocities) of all EPN sites obtained from processing the GPS 835-1680 weeks' data expressed in the ETRF2000 system for the 2005.0 epoch. ASG-EUPOS solution expressed for the 2005.0 epoch was used for the comparison. The differences between these two studies do not exceed $1 \mathrm{~cm}$ at any of the EPN sites of the ASG-EUPOS network. 


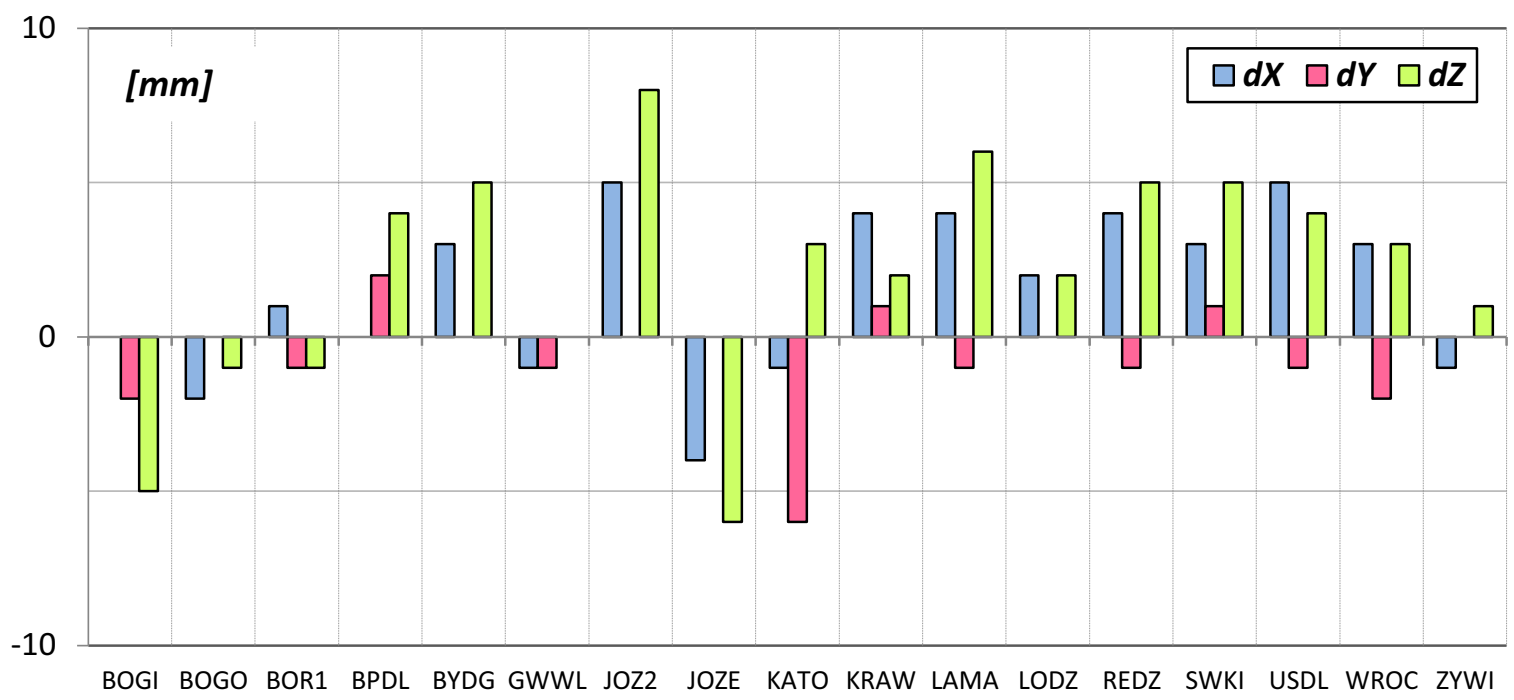

Fig. 1. A comparison of coordinates obtained from processing the ASG-EUPOS network data with coordinates from the most recent official distribution of the EPN

(ETRF2000 system, 2005.0 epoch)

Cumulative coordinates expressed both in the ITRF2008 and the ETRF2000 for the 2011.0 epoch were obtained as a result of the study. A reliable field of horizontal velocities and vertical movements in the territory of Poland is an important aspect of the obtained solution. The results were published in (Figurski et al, 2009, 2010). The studies gave only preliminary results because the analysis concerned short series (reliable values of velocity require observations of at least 30-months (Blewitt and Lavallee, 2002)). The field of horizontal velocities determined from longer ASG-EUPOS observations is presented in (Bogusz et al., 2012a) and (Bogusz et al., 2012b), while the models of vertical movements obtained from the GNSS data and precise leveling are presented in (Kontny and Bogusz, 2012). Horizontal velocities in the ETRF2000 system and vertical movements are presented in Fig. 2a and Fig. $2 b$.

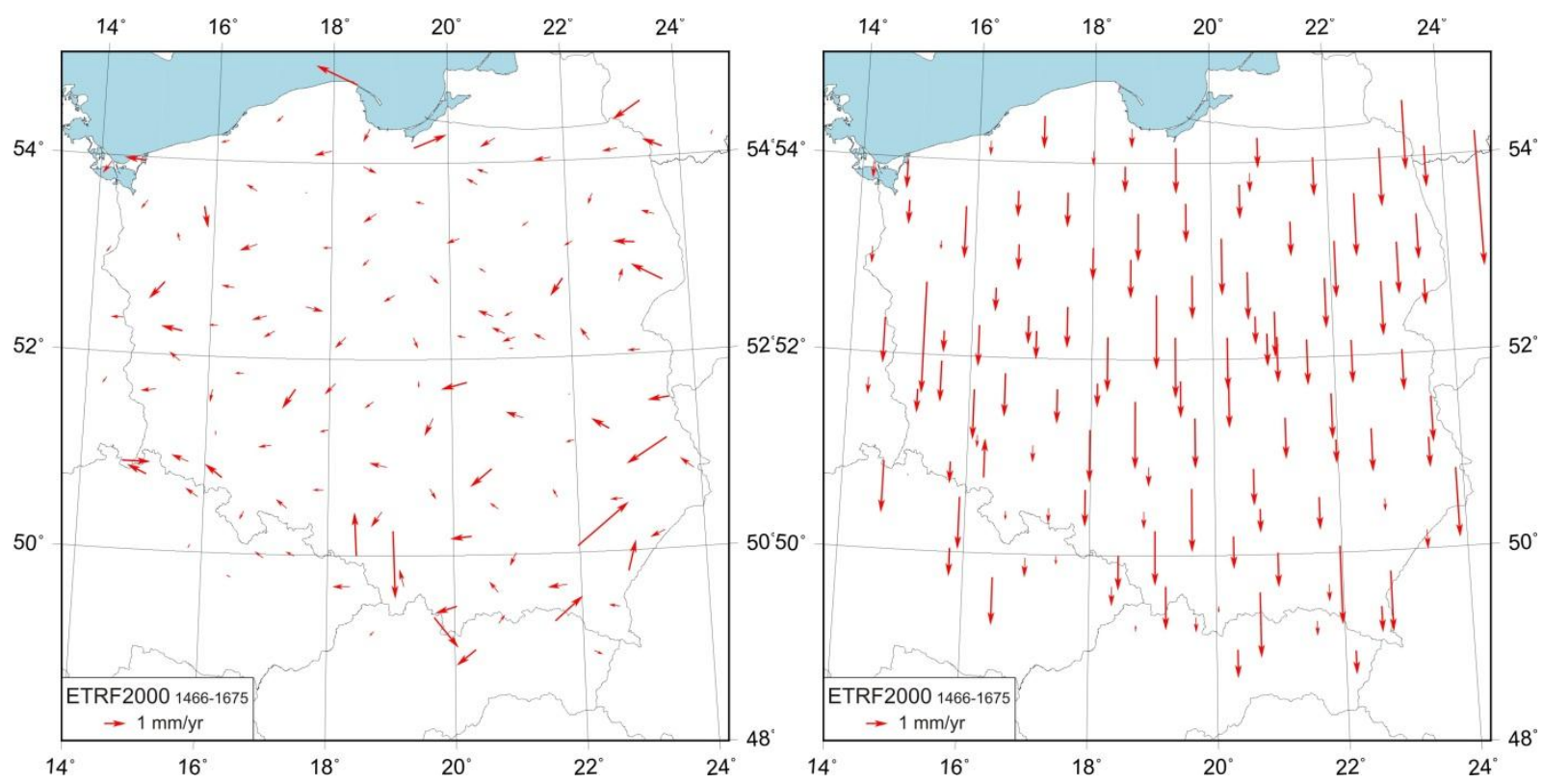

Fig. 2 a, b. Horizontal velocities in the ETRF2000 frame and vertical movements of the ASG-EUPOS sites 
The obtained cumulative solution was used as reference values in the module of coordinates monitoring created within the development grant Supporting Modules for Realtime Services of Polish GBAS (ASG+) realized by the Military University of Technology, Wrocław University of Environmental and Life Sciences and University of Warmia and Mazury in Olsztyn (Figurski et al., 2011). The current coordinates obtained with various delays depending on the applied products (ephemeries of the 'ultra rapid', 'rapid' and 'final' type and the Earth rotation parameters) are compared with the reference values which, due to a long time of data collecting and an appropriate strategy of processing, were assumed to be the closest values to the true coordinates. They enable to assess the current performance of individual sites and to analyze factors having negative impact on reliability of the obtained coordinates (e.g. snow cover effect) by analyzing the time series of the solutions (Bogusz et al., 2011). Fig. 3 shows an example of monitoring the KATO site using solutions obtained on the basis of the IGS 'final' type products. The monitoring enables to assess whether the current position of the site fits into the assumed error criterion $(0.01 \mathrm{~m}$ horizontally and 0.02 $\mathrm{m}$ for height with respect to the reference solution) and to assess the stability of its solutions.

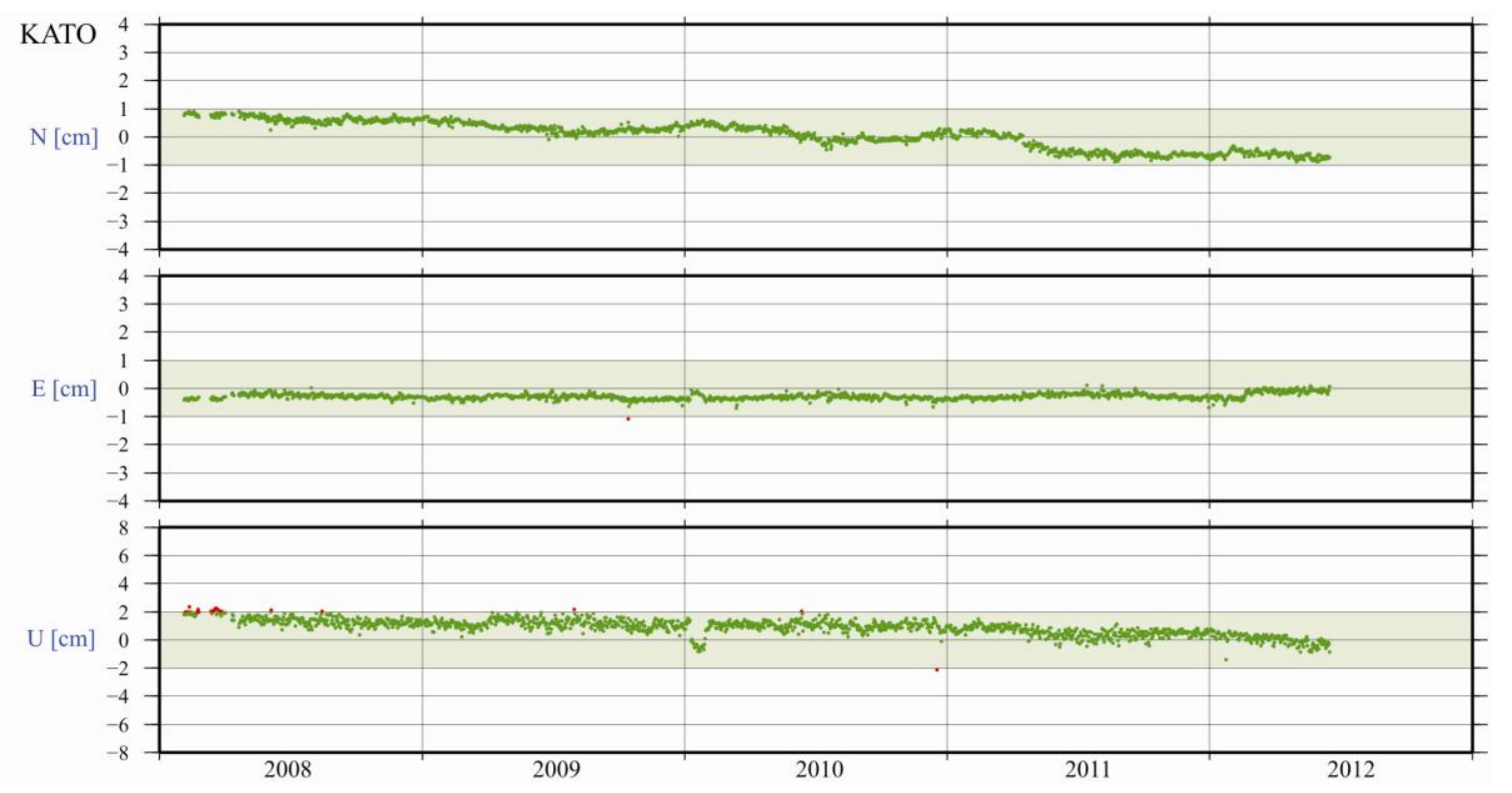

Fig. 3. ASG-EUPOS KATO site coordinates monitoring by means of comparing the diurnal coordinates values with the reference values (solutions obtained using the 'final' products, NEU components, ETRF2000 system).

\section{A FORECAST OF COORDINATES VALIDITY BASED ON THE OBTAINED VELOCITIES}

Although in Poland the values of the intraplate velocities are small in comparison with other states like Greece or Turkey, the velocities of some of the sites are significant enough (Fig. 2) that the sites should not be omitted in the process of the reference frame conservation.

On the basis of the obtained velocities (horizontal and vertical) a forecast of the coordinates' validity for 15 ASG-EUPOS sites of the EPN, i.e. sites constituting the fundamental warp of Poland, was prepared. The values defined by the Regulation of the Ministry of the Administration and Digitization concerning the geodesic, gravimetric and magnetic warps - accuracy of the sites' horizontal coordinates may not be worse than $0.01 \mathrm{~m}$ 
and $0.02 \mathrm{~m}$ for geodesic height - were assumed as the boundary criterion. The 2011.0 epoch was assumed as the reference epoch because most probably such epoch will be approved by the HOGC for expressing the catalogue coordinates. Selection of the epoch was determined by calibration measurements done in the EUREF-POL and POLREF sites constituting the main base warp together with the ASG-EUPOS sites. The horizontal and vertical velocities are not determined for these sites and thus it is not possible to determine their coordinates for a different epoch. Table 1 indicates that coordinates of some fundamental sites will exceed the assumed criterion (they will lose validity) in a period of time shorter than 10 years counting from the reference epoch (i.e. from 2011.0). This is indicated in red. In case of the horizontal components the problem concerns the KATO site (the criterion will be exceeded already in 2014) and GWWL (the criterion will be exceeded in 2021). The criterion required for the height component will be exceeded at more sites: GWWL (2015), KATO and WROC (2019), and BOGI and ZYWI (2021). It means that coordinates of these sites will have to be corrected in a few years to fulfill the accuracy criteria of the fundamental warp and to represent in a best possible way their actual position at any particular moment.

Table 1. Forecasted validity of catalogue coordinates of sites constituting the fundamental warp. The values of $0.01 \mathrm{~m}$ for the horizontal components and $0.02 \mathrm{~m}$ for the vertical component were assumed as the boundary criterion.

\begin{tabular}{|c|c|c|c|c|c|c|}
\hline \multicolumn{2}{|c|}{ ASG-EUPOS/EPN site } & vN $[\mathbf{m m} / \mathbf{y}]$ & vE $[\mathbf{m m} / \mathbf{y}]$ & $\mathbf{v U}[\mathbf{m m} / \mathbf{y}]$ & V hor. & V vert. \\
\hline BOGI & Borowa Góra & $-0,2$ & $-0,5$ & $-2,1$ & $\mathbf{2 0 3 0}$ & $\mathbf{2 0 2 1}$ \\
\hline BOR1 & Borowiec & $-0,3$ & $-0,4$ & $-1,4$ & $\mathbf{2 0 3 0}$ & $\mathbf{2 0 2 6}$ \\
\hline BPDL & Biała Podlaska & 0,0 & $-0,5$ & $-2,0$ & $\mathbf{2 0 3 0}$ & $\mathbf{2 0 2 1}$ \\
\hline BYDG & Bydgoszcz & $-0,1$ & $-0,4$ & $-1,5$ & $\mathbf{2 0 3 4}$ & $\mathbf{2 0 2 5}$ \\
\hline GWWL & Gorzów W. & $-0,7$ & $-0,6$ & $-4,9$ & $\mathbf{2 0 2 1}$ & $\mathbf{2 0 1 5}$ \\
\hline JOZ2 & Józefosław & 0,0 & $-0,2$ & $-0,1$ & $\mathbf{2 0 5 6}$ & $\mathbf{2 2 3 3}$ \\
\hline KATO & Katowice & $-3,0$ & 0,1 & $-2,5$ & $\mathbf{2 0 1 4}$ & $\mathbf{2 0 1 9}$ \\
\hline KRA1 & Kraków & $-0,6$ & $-0,2$ & 1,3 & $\mathbf{2 0 2 6}$ & $\mathbf{2 0 2 6}$ \\
\hline LAMA & Lamkówko & 0,2 & $-0,5$ & $-0,9$ & $\mathbf{2 0 3 1}$ & $\mathbf{2 0 3 4}$ \\
\hline LODZ & Łódź & $-0,2$ & 0,1 & $-1,6$ & $\mathbf{2 0 6 0}$ & $\mathbf{2 0 2 3}$ \\
\hline REDZ & Redzikowo & $-0,3$ & $-0,3$ & $-1,3$ & $\mathbf{2 0 3 4}$ & $\mathbf{2 0 2 6}$ \\
\hline USDL & Ustrzyki Dolne & 0,1 & $-0,4$ & $-1,3$ & $\mathbf{2 0 3 3}$ & $\mathbf{2 0 2 7}$ \\
\hline SWKI & Suwałki & 0.0 & -0.6 & -2.6 & $\mathbf{2 0 2 7}$ & $\mathbf{2 0 1 9}$ \\
\hline WROC & Wrocław & $-0,1$ & $-0,6$ & $-0,8$ & $\mathbf{2 0 2 7}$ & $\mathbf{2 0 3 7}$ \\
\hline ZYWI & Żywiec & 0,8 & $-0,2$ & $-1,9$ & $\mathbf{2 0 2 3}$ & $\mathbf{2 0 2 1}$ \\
\hline
\end{tabular}

Determining reliable velocities is a key issue in this case. Due to the specificity of the GNSS measurements, the horizontal velocities are more reliable than the vertical ones. It means that monitoring of the solutions (coordinates) from the reference sites described above is indispensable for ensuring that the current solutions fulfill the assumed accuracy criterion and differ from the catalogue values not more than $0.01 \mathrm{~m}$ (horizontal components) and 0.02 $\mathrm{m}$ (vertical component). It is also necessary to conduct repeated processing which enables to determine the velocities using new observations done according to the EPN (EPN sites classification takes into consideration first of all repeatability of velocity values determined in subsequent processing (Bruyninx et al., 2009)). It is also necessary to consider that the site velocity is only one of the factors having influence on the value of the current solutions. Determination of others, like the snow cover effect or antenna dislocation (which may occur 
first of all in mining areas) is possible only due to reference sites monitoring. Additionally, every change of equipment (especially the antennas) may cause discontinuity of coordinates and requires introducing new values of coordinates at the modified site (despite taking the new antenna into consideration during processing).

The accuracy criteria for the remaining ASG-EUPOS sites constituting the main base warp are not explicitly defined in the Regulation. However, the mean error of the newly established sites of such a warp should not exceed $0.01 \mathrm{~m}$ and $0.02 \mathrm{~m}$ (for the horizontal components and height, respectively) with respect to the fundamental warp. Thus, such criteria were assumed for analysis of all the ASG-EUPOS sites. Due to the referential function of the system, all discrepancies of the current observations from the catalogue values will have a negative influence on measurements done using them, therefore the monitoring should include all sites in the system and not only the sites of the main fundamental warp. Similarly as for the EPN/ASG-EUPOS sites, catalogue coordinates' temporal validity analyses were made using the determined horizontal and vertical velocities.

Fig. 4 presents the ASG-EUPOS sites which horizontal coordinates will exceed the assumed criterion in less than 10 years (Fig. $4 \mathrm{a}$ - red), less than 15 years (Fig. $4 \mathrm{~b}$ - yellow) and those which coordinates will not require correction in the period of time (Fig. 4c - green). These forecasts are of rough character and are based on the values of the horizontal velocities. Fig. 5 presents results of analogous analyses done for the height component. In this case, significantly more sites will exceed the assumed criterion in less than 10 years. However, it is necessary to remember the lower reliability of the vertical velocities. The decision concerning introducing coordinates changes should be based on the analysis of the results of coordinates monitoring. It is obvious that correcting the vertical component will require changes of the horizontal component (coordinates are determined in the Cartesian orthogonal XYZ coordinate system and then recalculated for the ellipsoidal coordinates system). Introducing catalogue coordinates determined for an epoch ,ahead” (e.g. 2015.0) using known values of velocities, would be worth considering as a method of prolonging validity of the catalogue coordinates. However, such a solution is not feasible in case of Poland due to lack of velocities for all sites of the main warp.

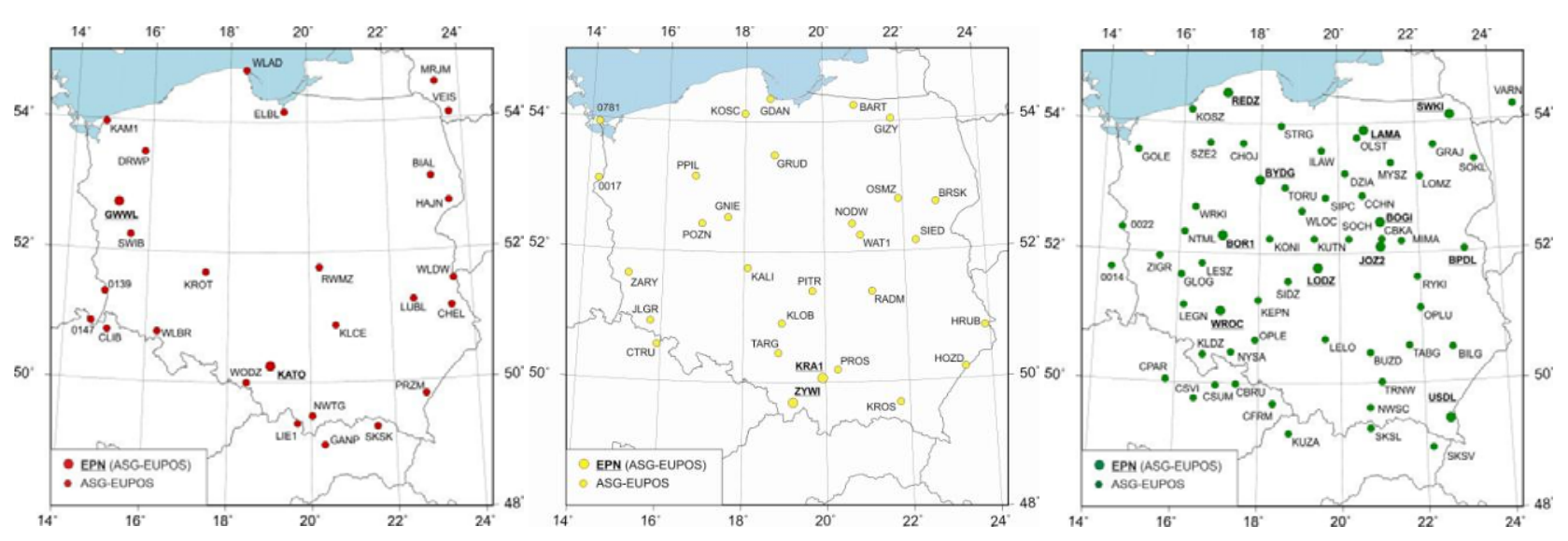

Fig. 4 a, b, c. ASG-EUPOS sites which horizontal coordinates will require correction by 2021 (in Fig. $4 a-$ red), by 2026 (in Fig. 4b - yellow) and those which coordinates will not change more than the assumed criterion in the period of time (in Fig. $4 \mathrm{c}-$ green).

2011.0 was assumed as the reference epoch. 


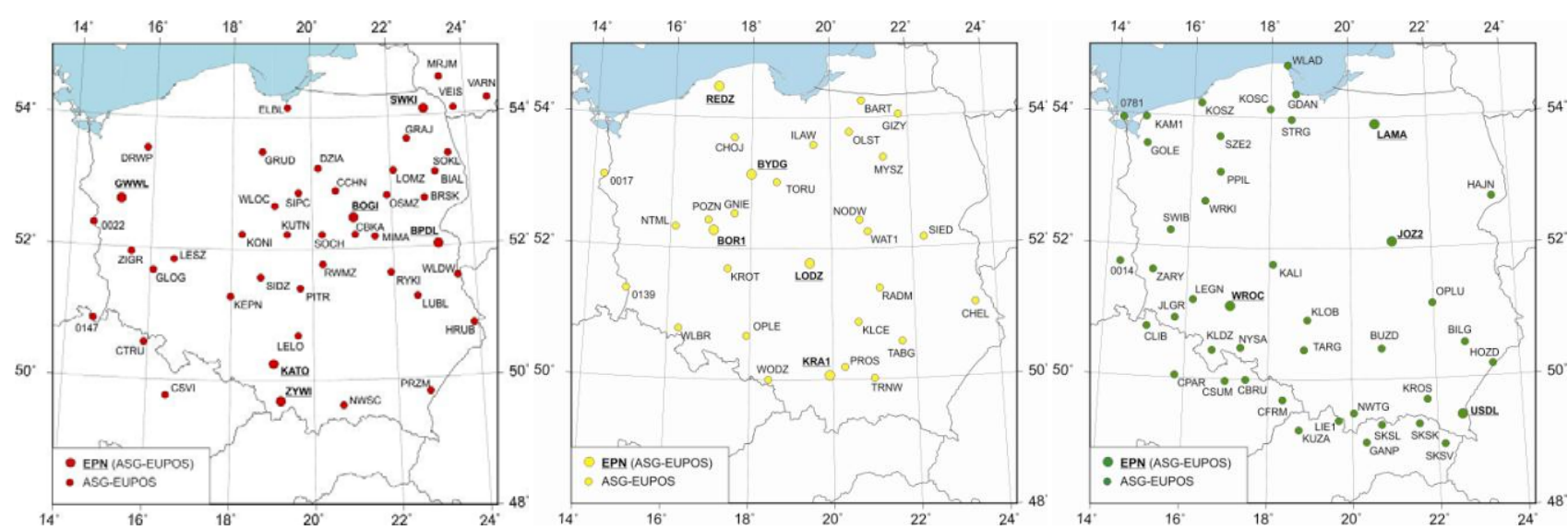

Fig. 5 a, b, c. ASG-EUPOS sites which geodesic heights will require correction by 2021 (in Fig. 5a red), by 2026 (in Fig. 5b - yellow) and those which coordinates will not change more than the assumed criterion in the period of time (in Fig. 5c-green).

2011.0 was assumed as the reference epoch.

The above presented analyses indicate that due to continuous GNSS observations at the warp sites it is advised to change the common attitude to the warp - its coordinates are not constant values. They should be monitored for changes related with the site movement and periodically corrected during modernization (anticipated once in 10 years for warps established using satellite methods). Possible need for earlier modification of the catalogue coordinates will be noticed during monitoring of the current solutions. The analyses show also that introducing a kinematic model (requiring determination of the warp coordinates for the epoch of observation) is not necessary for realization of the ETRS89 system in Poland, and the required accuracies should be ensured by periodical changes of the coordinates of the individual sites. It is, however, recommended to conduct repeated processing for the entire network according to the EUREF standards for taking the current GNSS observations into consideration. The values of the horizontal velocities in Poland should have no influence on exceeding the accuracy criteria set for the sites of the detailed warp (required accuracy is 0.07 $\mathrm{m})$.

\section{CONCLUSIONS AND OUTLOOK}

The aim of the paper is to present the results of the analyses concerning the temporal validity of the catalogue coordinates of the ASG-EUPOS system sites with respect to the new legal regulations. Coordinates constituting reference values in the system of coordinates monitoring developed in the CAG of the MUT and velocities which were used for forecasting changes of the coordinates in the several following years were determined using four-year observations. Although in Poland the values of the intraplate velocities are not big, periodical changes of the catalogue coordinates of the ASG-EUPOS system will be necessary. The paper shows for which sites the changes should be introduced at first. Lack of periodical updating of the coordinates realizing the reference system will cause lack of fulfillment of the assumed consistency criterion ( $1 \mathrm{~cm}$ for the horizontal components and $2 \mathrm{~cm}$ for the geodesic height). Although it is a problem of some sites, it is worth to maintain uniformity of the elaboration and perform periodic repeated processing for the entire network, especially that relatively easy replacement of the catalogue coordinates is an advantage of the warp realized by permanent GNSS sites. This modification is introduced in the system and it does not require involvement of the system user. In case of Poland it is not indispensable to introduce a kinematic warp (recalculating the coordinates for a specific epoch) but it is necessary to monitor current solutions for reliable maintenance of the ETRF2000 system and for 
assessment of the influence of the factors causing decreasing accuracy of the current solutions (e.g. snow cover, possible failure of equipment, antenna replacement causing discontinuity of the solutions). The coordinates and velocities should be determined again when a greater number of observations are collected (quasi-kinematic warp). At the same time, it is necessary to remember that the vertical component is determined ambiguously due to the GPS system character and small values of the vertical movements (Kontny and Bogusz, 2012).

\section{ACKNOWLEDGEMENT}

The research was partially supported by the grant No. NR09-0010-10/2010 of the National Centre for Research and Development.

The author acknowledges helpful discussions with Centre of Applied Geomatics (Military University of Technology) Staff, especially Janusz Bogusz and Mariusz Figurski.

\section{REFERENCES}

International Association of Geodesy Sub-Commission 1.3 on Regional Reference Frames, Working Group on Regional Dense Velocity Fields, 2007-2011: http://epncb.oma.be/IAG/

Altamimi Z., P. Sillard, C. Boucher, CATREF Software: 2004, Combination and Analysis of Terrestrial Reference Frames. Publication LAREG SP08, Institut Géographique National.

Altamimi Z., Boucher C.: 2008, Memo: Specifications for reference frame fixing in the analysis of a EUREF GPS campaign (http://etrs89.ensg.ign.fr/memo-V8.pdf).

Blewitt G., Lavallée D.: 2002, Effect of annual signals on geodetic velocity. J. Geophys. Res., 107(B7), 2145, doi:10.1029/2001JB000570.

Bogusz J., Figurski M., Kroszczyński K., Szafranek K.: 2011, Investigation of environmental influences to GNNS coordinates. Acta Geodynamica et Geomaterialia Vol 8, No. 1 (161), 2011, pp. 5-15.

Bogusz J., Figurski M., Kontny B., Grzempowski P.: 2012a, Unmodeled effects in the horizontal velocity fields: ASG-EUPOS case study. Artificial Satellites Vol. 47, No. 2, 2012, DOI: 10.2478/v10018-012-0014-x, pp. 67-79.

Bogusz J., Figurski M., Kontny B., Grzempowski P.: 2012b, Horizontal velocity field derived from EPN and ASG-EUPOS satellite data on the example of south-western part of Poland. Acta Geodynamica et Geomaterialia Vol 9, Nr 3 (167), 2012, pp. 349-357.

Bruyninx C., Altamimi Z., Caporali A., Kenyeres A., Lidberg M., Stangl G., Torres J.A.: 2009, Guidelines for EUREF Densifications.

Caporali A., Lidberg M., Stangl G.: 2011, Lifetime of ETRS89 coordinates. Presented at the EUREF 2011 Symposium, May 25-27, 2011, Chisinau, Moldova.

Dach, R., U. Hugentobler, P. Fridez, M. Meindl (Eds): 2007, Bernese GPS Software Version 5.0. User manual, Astronomical Institute, Universtiy of Bern.

Figurski M., Kamiński P., Kroszczyński K., Szafranek K.: 2009, ASG-EUPOS monitoring with reference to EPN. Artificial Satellites Vol. 44, No. 3, pp. 85-94; DOI: 10.2478/v10018-009-00227.

Figurski M., Kamiński P., Kroszczynski K., Szafranek K.: 2010, Preliminary results of the ASGEUPOS processing in the context of EPN densification and system monitoring. Bulletin of Geodesy and Geomatics Vol. LXIX N. 2-3, 2010, pp. 223-237.

Figurski M., Bogusz J., Bosy J., Kontny B., Krankowski A., Wielgosz P.: 2011, ASG+": project for improving Polish multifunctional precise satellite positioning system. Reports on Geodesy No 2 (91) 2011, pp. 51-58. 
Kenyeres A.: 2009, Maintenance of the EPN ETRS89 coordinates. Presented at the EUREF TWG 2009 Spring Meeting, Feb. 26-27, 2009, Budapest (http://www.euref.eu/TWG/EUREF\%20TWG\%20minutes/49-Budapest2009/03-eETRSmaint_TWGrepBP.pdf).

Kenyeres A.: 2012, The implementation of IGS08 in the EPN ETRS89 maintenance products. Published online (ftp://epncb.oma.be/pub/station/coord/EPN/IGS08_densification_V4.pdf) in October 2012.

Kontny B., Bogusz J.: 2012, Models of vertical movements of the Earth crust surface in the area of Poland derived from leveling and GNSS data. Acta Geodynamica et Geomaterialia, v. 9, No. 3(167), 2012, pp. 331-337.

Lidberg M.: 2012, The EUREF working group on deformation models. Presented at the EUREF 2012 Symposium, June 6-8, 2012, Paris, France (http://euref2012.ign.fr/pdf/s3/3_8.pdf).

Szafranek K., Bogusz J., Figurski M.: GNSS reference solution for permanent sites stability monitoringand geodynamical investigations: an ASG-EUPOS case study. (Paper submitted to Acta Geodynamica et Geomaterialia in October 2012).

Regulation of the Minister of Administration and Digitalization concerning geodetic, gravimetric and magnetic warps: $14^{\text {th }}$ of February 2012, (Dz. U. Nr 63, poz. 352).

Regulation of the Polish Government concerning national spatial reference system (project).

http://igscb.jpl.nasa.gov/

http://www.asgeupos.pl/

http://www.epncb.oma.be

Personal communications (2012) with Elmar Brockmann, Alessandro Caporali, Jan Dousa, Heinz Habrich, Ambrus Kenyeres, Martin Lidberg and Guenter Stangl.

Received: 2012-11-12,

Reviewed: 2012-11-21, by A. Caporali,

Accepted: 2012-11-23. 